\title{
UNIVERSITYOF
}

FORWARD

THINKING

WESTMINSTER用

WestminsterResearch

http://www.westminster.ac.uk/westminsterresearch

\section{AR-based Technoself Enhanced Learning Approach to Improving Student Engagement}

Jin, L., Huang, W. and Wen, Z.

This is the published version of the paper 'AR-based Technoself Enhanced Learning Approach to Improving Student Engagement' by Jin, L., Huang, W. and Wen, Z., which was presented at the 8th Annual International Conference on Education and New Learning Technologies, Barcelona, Spain 4th-6th July 2016.

The WestminsterResearch online digital archive at the University of Westminster aims to make the research output of the University available to a wider audience. Copyright and Moral Rights remain with the authors and/or copyright owners.

Whilst further distribution of specific materials from within this archive is forbidden, you may freely distribute the URL of WestminsterResearch: ((http://westminsterresearch.wmin.ac.uk/)).

In case of abuse or copyright appearing without permission e-mail repository@westminster.ac.uk 


\title{
AR-BASED TECHNOSELF ENHANCED LEARNING APPROACH TO IMPROVING STUDENT ENGAGEMENT
}

\author{
L. Jin', W. Huang ${ }^{1}$, Z. Wen ${ }^{2}$ \\ 1 University of Westminster (UNITED KINGDOM) \\ 2 GSM London (UNITED KINGDOM) \\ I.jin02@westminster.ac.uk,w.huang01@westminster.ac.uk,zwen@gsmlondon.ac.uk
}

\begin{abstract}
The emerging technologies have expanded a new dimension of self - 'technoself' driven by sociotechnical innovations and taken an important step forward in personalised active learning. In particular, Augmented Reality (AR) research has matured to a level to facilitate augmented learning, which is defined as an on-demand learning technique where the learning environment adapts to the needs and inputs from learners. In this paper we firstly study the role of Technology Acceptance Model (TAM) applied in Technology Enhanced Learning (TEL) on how learners come to accept and use a new technology. Then we present the design methodology of a technoself system for adaptive active learning and introduce technoself enhanced learning as a novel pedagogical model to improve student engagement by shaping personal learning focus and setting. Furthermore we describe the design and development of an AR-based learning system and discussed its key features on how to connect with learners and further create new ways to engage. Finally, we validate and evaluate the AR-based technoself enhanced learning approach in a broad diversity of learning practices including constructive activities and analytical activities through experimental AR-based learning apps for digital interpretation.
\end{abstract}

Keywords: Technology Enhanced Learning, Augmented Reality, Technoself, and Student Engagement.

\section{INTRODUCTION}

Technology Enhanced Learning (TEL) research has increasingly focused on emergent technologies such as Augmented Reality (AR), game and mobile to improve self-motivation and self-engagement of the learners in an appealing hybrid learning environments. These researches take advantage of technological innovations in hardware and software across different platforms and devices including tablets, phablets and even game consoles and their increasing popularity for pervasive learning with the significant development of personalization processes which place the student at the centre of the learning process [1][2][3]. Nowadays, AR research has matured to a level to facilitate augmented learning, which is defined as an on-demand learning technique where the learning environment adapts to the needs and inputs from learners [4][5]. Martin pointed out that the evolution of AR to mobile platform is a promising trend but AR is still in its infancy stage in education [6]. Wu believed that the unique value of $A R$ based learning can only be discovered by carrying out research on investigating the affordance and characteristics of AR in education [7]. Radu reviewed the studies on learning in AR and concluded that there are both positive impacts, e.g. increased content understanding, learning of spatial structures etc., and negative impacts, e.g. usability difficulties, ineffective classroom integration etc [8].

In this paper, the role of Technology Acceptance Model (TAM), which is one of the most influential theories applied in TEL on how learners come to accept and use a new technology, will be studied. Based on the theory, we present the design methodology of the technoself approach for pervasive learning. It introduces technoself enhanced learning to improve student engagement and then describes the development of an AR-based interactive digital interpretation system for augmented learning. Finally, we validate and evaluate the AR-based technoself enhanced learning approach through experimental learning practices. As a result, the novel pedagogical approach has fostered a vibrant learning environment that supports learners' diversity and individual needs while enhancing student learning experience with constructive engagement. 


\section{METHODOLOGY: TECHNOSELF ENHANCED LEARNING APPROACH}

Technology Acceptance Model (TAM) is one of the most influential theories on how people come to accept and use a technology. The theory suggests that a person's behaviour is determined by the individual's intention to perform the behaviour [9]. TAM highlights a number of factors that influence one's decision about how and when people will use a technology. The model has been continuously expanded in the unified theory of acceptance and use of technology, which was motivated by the need to predict the usability of new technology and to identify and stimulate the use of new technology [10]. The TAM has facilitated strategies development to increase the acceptance of a new technology. Furthermore, the applicability of TAM has been expanded by implementing theories of learning behaviour in TEL.

The latest scientific and technological innovations have had a profound effect on one's self-concept and the ways of self-construction through TEL. The self-system is an interconnected network of beliefs that helps a person to make sense of the world and decide what goals and tasks to pursue. The enhancement of self-concept and motivation is widely valued as a critical goal and a positive outcome of education [11]. While facilitating creativity and self-esteem, emergent technology such as AR, gaming, mobile and cloud computing has advanced to such an extent that nowadays affects one's self-concept and the ways of learning. These result in the formation of 'technoself' which supports the dynamic evolving self through exploring new experiences or information, and further developing talents and potential in a creative learning environment.

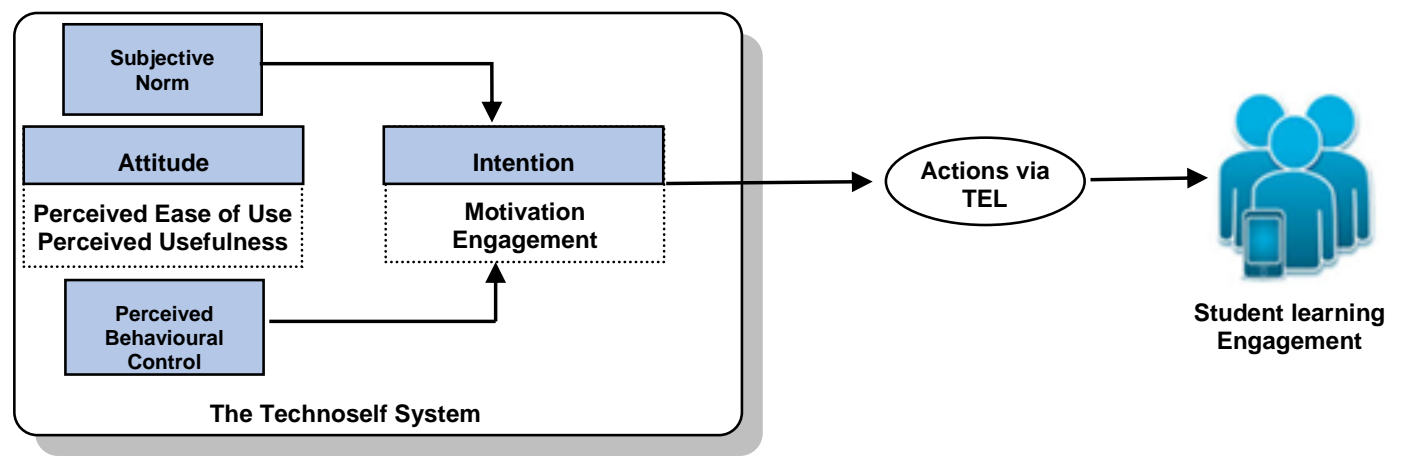

Fig. 1. Technoself enhanced learning approach

In this paper, we propose a technoself enhanced learning approach to improving learner engagement and personal motivation. As shown in Figure 1, the Technology Acceptance Model (TAM) is embedded in a technoself system by applying various factors involving learners' behaviour in the context of Technology Enhanced learning (TEL). Two cognitive beliefs are involved in this model for TEL: perceived usefulness and perceived ease of use. Perceived usefulness refers to the degree to which a learner believes that using a particular technology would enhance learning performance. Perceived ease of use is regarded as the degree to which a person believes that using a particular technology for learning would be free of effort. Subjective norm is the perceived social pressure to engage or not to engage in learning. Perceived behavioral control refers to learners' perceptions of their ability to perform learning actions in this system.

\section{AR-BASED LEARNING SYSTEM DEVELOPMENT}

The challenge in successfully developing technoself enhanced learnings services lies in the complexity of developing adaptive learning experiences based on personal learning focus and setting. Research in learner-centric active learning technologies has so far highlighted Augmented Reality $(A R)$, which can bring a new level of immersion into a learning environment to adapt to the needs and inputs from learners [1]. Since the term "augmented reality" was coined by Caudell and Mizel in early 1990s, its technological breakthrough has made many changes in various fields such as design and manufacturing, culture heritage, and education [12][13][14]. For example, an AR based method was developed to allow the users to have a much more completed picture of the cultural heritage collection including its states and associated historical information in the past, by encoding context-dependent information into the collection object [13]. The research also tried to address issues on how effective 
semantic transitions can be achieved in a user friendly way and how user can intuitively navigate between objects. AR on mobile devices has been introduced in recent years to innovate library uses and services, which include augmenting physical books tacks browsing, library navigation, optical character recognition, facial recognition and building identification mobile software [15].

AR technology provides an interactive hybrid environment, in which the virtual content (e.g. 3D model, sound, video, text-based information or GPS data) overlays with a live physical real world. It is related to a more general concept called mixed reality, where the merging of real and virtual worlds to produce new environments to allow physical and digital objects to co-exist and interact in real time. The augmentation takes place in real-time and in semantic context with environmental elements. Meanwhile it offers the following key features to connect with users and further create new ways to engage.

- Combine a range of interactive capability and rich 3D content

- Overcome the limitation of physical world by coupling with digital content

- Analyse multimodal interaction strategy to manipulate content and reveal details

Thanks to these technical innovations, AR functions by enhancing one's current perception of reality and further affects one's perceived behavioural control in the technoself system proposed in this paper. By adopting VR as a novel creative learning technology, it opens up new opportunities for TEL to increase learner's engagement and gain greater understanding. It helps learners hear, see and feel their surroundings in new means, which enables various degrees of immersion in a vibrant learning environment. Immersion is the subjective impression that one is participating in a comprehensive, realistic experience. The more a virtual immersive experience is based on design strategies that combine actional, symbolic, and sensory factors, the greater the participant's suspension of disbelief that she or he is "inside" a digitally enhanced setting. Based on the design methodology proposed in Section 2, we developed an AR-based learning system for digital interpretation. The system was designed with basis on three main components, as illustrated in Figure 2: Tracking Unit, Processing Unit, and Visual Unit. The infrastructure tracker in Tracking Unit was responsible for collecting data from diverse physical based learning settings in real world (e.g. classrooms, museums, and libraries); sending them to the Processing Unit, which mixed the virtual learning content with the real learning scenario and sent the result to the Visual Unit to form the augmented learning environment.

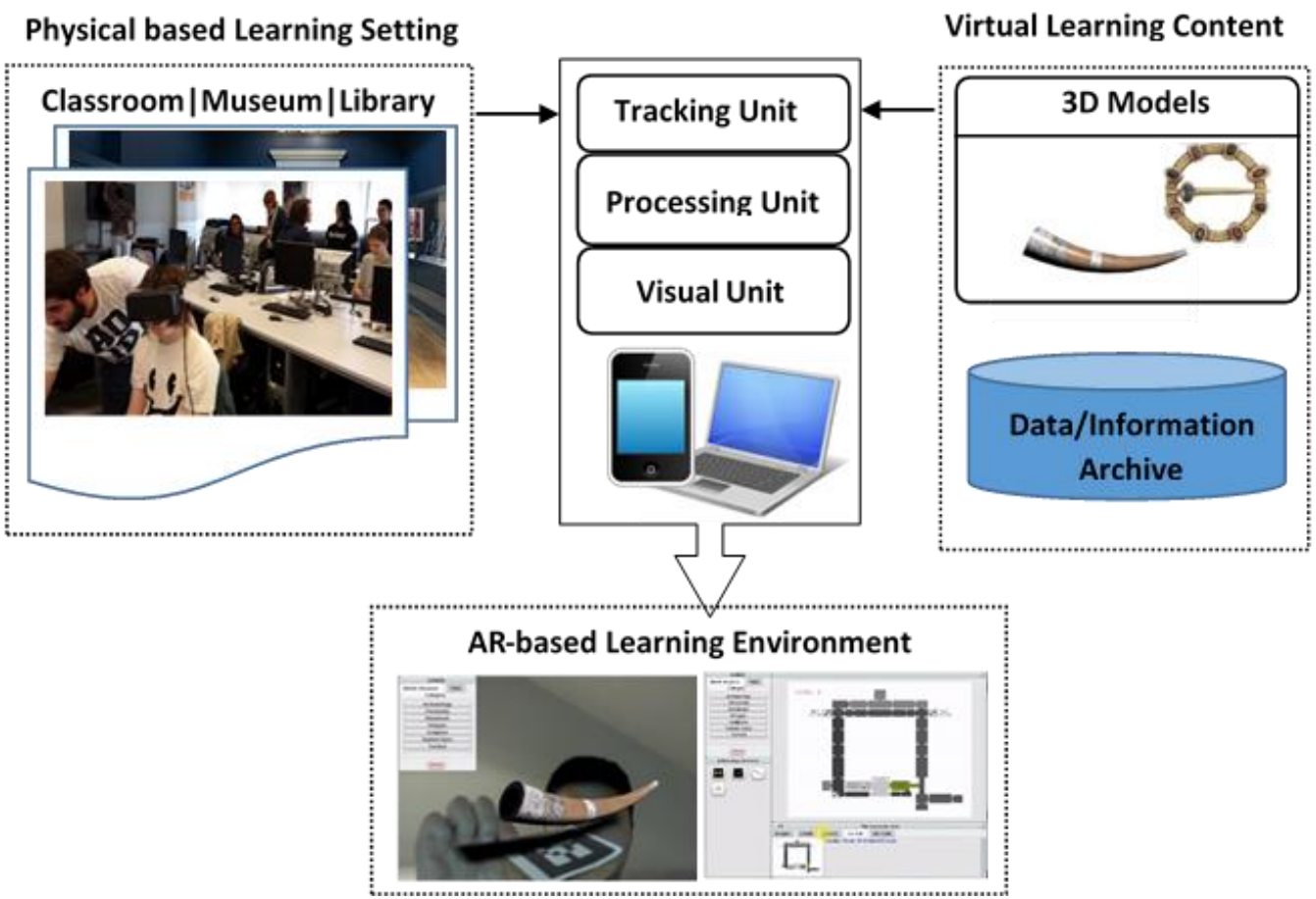

Fig. 2. AR-based learning system for digital interpretation 
Nowadays, the most innovations in TEL have been focused on more learner-centric solutions in which student inquiry, activity, and engagement are key requirements that e-learning application developers must satisfy. In this pedagogical research project, the AR-based learning system highlights the learner-centric approach through the technoself system and will then greatly advance the next generation of TEL by:

- moving toward more constructive approaches to learning environments, in which the learner is active in composing, and evaluating knowledge, information, and artefacts;

- embedding collaboration via social interaction within learning opportunities and experiences through social networking;

- evolving personalization of the learning experience and process so that it can dynamically recognize and support diverse learner needs and requirements;

\section{SYSTEM VALIDATION AND DISCUSSION}

To validate the AR-based learning system, we firstly prototyped an interactive digital interpretation app for museums, which helps visitors to learn historical and archaeological art crafts and collections in British Museum and Victoria and Albert Museum (V\&A). As shown in Figure 2, the AR-based learning system successfully superimposes digital learning materials including 3D models of collections and other guidance information into the real context by using QR codes. This prototype allows visitors to control their own learning pace, through the active interactions within the hybrid learning environment. As there is a high demand for AR-based learning to be run on portable devices such as mobile phones and tablets, etc [16], we then developed a mobile AR solar exploration app in Java with Wikitude SDK, which runs on an Android smartphone to help young children learn about the solar system and the planets in an exciting way. As shown in Figure 3, children can observe the planets hovering above the desk or table like the holograms in science fiction movies. As a result, the learning process becomes fun and exciting so that children get inspired to delve deeper into the topic.
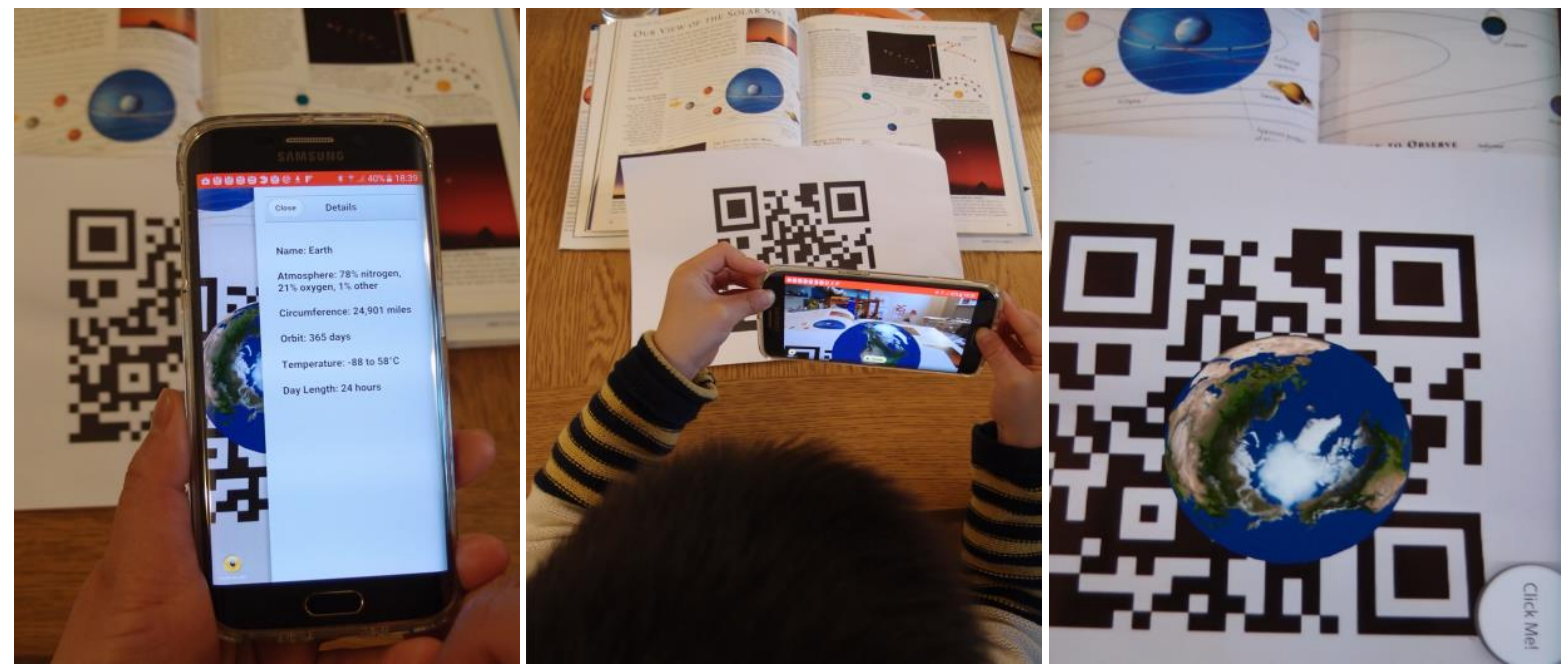

Fig. 3. A mobile AR-based solar exploration learning app

We further incorporate games, videos, and social networking services (e.g.YouTube, Facebook, and Wiki) into the AR-based learning system to enrich and deliver the learning content, which can be geared toward learner's needs and learners can stimulate discovery and gain greater understanding. The system successfully demonstrates that AR can provide rich contextual learning environment and contents tailored for individuals. Such Augment Learning can bridge this gap between the theoretical learning and practical learning, and focus on how the real and virtual can be combined together to fulfil different learning objectives, requirements, and even environments. It shows that $A R$ is well aligned with constructive learning strategies, as learners can control their own learning and manipulate objects that are not real in augmented environment to derive and acquire understanding and knowledge in a broad diversity of learning practices including constructive activities and analytical activities. 
Based on sound pedagogic strategies, the AR-based technoself enhanced learning system offers interactive rich content, activities, and collaboration adapted to learners' specific needs and influenced by their specific preferences and context. It has great potential to enhance student learning experience with constructive engagement, which is seen to be strongly valued to all participants in TEL. It is much easier and faster to achieve learning tasks and complete Kolb's experiential learning cycle via technoself enhanced learning. Kolb suggests that there are four stages in learning which follow from each other: the Concrete Experience stage is followed by the Reflective Observation stage on a personal basis experience. This then be followed by the derivation of general rules describing the experience, or the application of known theories to the Abstract Conceptualization stage, and hence to the construction of ways of modifying the next occurrence of the experience in Active Experimentation stage, leading in turn to the Concrete Experience stage [17].

\section{CONCLUSIONS AND FUTURE WORK}

In this paper, we presented the design methodology of a technoself enhanced approach for personalised active learning. By adopting AR as a creative learning technology, the technoself enhanced learning suggests a learner-centric solution for augmented learning. We then described the design and development of an AR-based learning system and discussed key features on how to connect with learners and further create new ways to engage. Finally, we validated and evaluated the AR-based technoself enhanced learning approach to enhancing the student motivation and engagement in the learning process by successfully prototyping two novel interactive learning apps: one is for digital interpretation of museum collections, another is for exploration of the solar system. By incorporating mobiles, gaming, voice recognition, and multimodal interaction through the AR-based learning system, the 'technoself' plays a major role in how learners perceive learning settings and how they behave in response to different learning setting and situations. As a result, the novel pedagogical approach has fostered a vibrant learning environment that supports learners' diversity and individual needs. This diversity can include learner differences in prior knowledge, competencies, learning style, communication preferences, cognitive style, and so on. However, the challenges of providing active and stimulating learning experiences that support learner collaboration, self-construction, and selfreflection remains key to successful in the next generation of TEL.

In addition, although AR has rapidly become an important technology to bridge the virtual learning world and the physical based learning environments, there are still many barriers to its adoption in education. AR is limited by a highly fragmented ecosystem of hardware platforms and operating systems; a lack of standards for sharing data and supporting interactions; and technical barriers in optics, 3-D capabilities, authoring tools, and interaction methods, which require the further technical breakthrough. Furthermore, such advanced technologies are sometimes for the more tech-savvy learners due to the level of difficulty for ease of use. These cause some research debates on the impact of self-efficacy in TEL, which refers to a person's belief in his or her ability to succeed in a particular learning situation. Self-efficacy plays a major role in how goals, tasks, and challenges are approached [18]. In our future work, we intend to examine how self-efficacy affects the technoself system in TEL from intentional states including motivation and engagement.

\section{REFERENCES}

[1] Bacca, J., Baldiris, S., Fabregat, R., Graf, S., \& Kinshuk. (2014). Augmented Reality Trends in Education: A Systematic Review of Research and Applications. Educational Technology \& Society, 17 (4), pp.133-149.

[2] Johnson, L., Adams Becker, S., Estrada, V., \& Freeman, A. (2014). Horizon report 2014 Higher education edition. Austin, TX:The New Media Consortium.

[3] Cheng, K.-H., \& Tsai, C.-C. (2012a). Affordances of augmented reality in science learning: Suggestions for future research. Journal of Science Education and Technology, 22(4), pp.449462. doi:10.1007/s10956-012-9405-9

[4] Klopfer, E. (2008.) Augmented Learning: Research and design of mobile educational games. MIT Press, Cambridge.

[5] Doswell, J. (2006). Augmented Learning, Augmented Learning: Context-Aware Mobile Augmented Reality Architecture for Learning", In the Proceedings of the Sixth IEEE 
International Conference on Advanced Learning Technologies, IEEE Computer Society Washington, DC, pp.1182-1183.

[6] Martin, S., Diaz, G., Sancristobal, E., Gil, R., Castro, M., \& Peire, J. (2011). New technology trends in education: Seven years of forecasts and convergence. Computers \& Education, 57(3), pp.1893-1906.

[7] Radu, I. (2014). Augmented reality in education: a meta-review and cross-media analysis. Personal and Ubiquitous Computing, 18(6), pp.1-11.

[8] Wu, H.-K., Lee, S. W.-Y., Chang, H.-Y., \& Liang, J.-C. (2013). Current status, opportunities and challenges of augmented reality in education. Computers \& Education, 62, pp.41-49.

[9] Davis, F.D. (1989). Perceived usefulness, perceived ease of use and user acceptance of information technology. MIS Quarterly, 13(3), pp. 319-339.

[10] Venkatesh, V., Morris, M. G., Davis, G. B. and Davis, F. D. (2003). User acceptance of information technology: Toward a unified view. MIS Quarterly 27 (3): pp. 425-478.

[11] Hsu, Y., Hung, J., and Ching, Y. (2013). Trends of educational technology research: more than a decade of international research in six SSCl-indexed refereed journals. Educational Technology Research and Development, 61(4), pp. 685-705.

[12] Caudell, T.P. and Mizell, D.W. (1992). Augmented reality: An application of heads-up display technology to manual manufacturing processes. In Proceeding Hawaii International Conference on Systems Sciences, Kauai, HI, USA. pp. 659-669.

[13] Gergatsoulis, M., Lilis, P.D., Lourdi, I., and Papatheodorou, C. (2009). "Representing contextdependent information in cultural collections," International Journal of Semantic Computing, vol. 3, no. 2, pp. 255-276.

[14] Fallavollita, P., Blum, T., Eck, U., Sandor, C., Weidert, S., Waschke, J., \& Navab, N. (2013). Kinect for interactive AR anatomy learning. Proceedings of 2013 IEEE International Symposium on Mixed and Augmented Reality. pp. 277-278.

[15] Hahn, J. (2012). "Mobile augmented reality applications for library services," New Library World, vol. 113, no. 9/10, pp. 429-438.Azuma, R. (1997). A survey of augmented reality. Presence-teleoperators and Virtual Environments, 6(4), 355-385.

[16] Azuma, R., Billinghurst, M., and Klinker, G. (2011). Special section on mobile augmented reality. Computers \& Graphics, 35(4).

[17] Kolb, D. A. (1984) Experiential learning: Experience as the source of learning and development (Vol. 1). Englewood Cliffs, NJ: Prentice-Hall.

[18] Joo, Y., Bong, M., and Choi, H. (2000). Self-efficacy for self-regulated learning, academic selfefficacy, and internet self-efficacy in web-based instruction. Educational Technology Research and Development, 48, pp.5-17. 